\title{
NERVE GROWTH FACTOR IN BRAIN DISEASES
}

\author{
Stefania Ciafrè ${ }^{1}$, Valentina Carito ${ }^{2 *}$, Giampiero Ferraguti ${ }^{3}$, Antonio Greco ${ }^{4}$, Massimo Ralli ${ }^{4}$, \\ Paola Tirassa $^{2}$, George N. Chaldakov ${ }^{5}$, Marisa Patrizia Messina ${ }^{6}$, Maria Luisa Attilia ${ }^{7}$, \\ Rosaria Ceccarelli $^{7}$, Luigi Tarani ${ }^{8}$, Mauro Ceccanti ${ }^{7}$, and Marco Fiore ${ }^{2 *}$ \\ ${ }^{1}$ Institute of Translational Pharmacology, IFT-CNR, Rome, Italy \\ ${ }^{2}$ Institute of Cell Biology and Neurobiology, IBCN-CNR, Rome, Italy \\ ${ }^{3}$ Department of Experimental Medicine, Sapienza University of Rome, Italy \\ ${ }^{4}$ Department of Sense Organs, Sapienza University of Rome, Italy \\ ${ }^{5}$ Department of Anatomy and Cell Biology, Medical University, Varna, Bulgaria \\ ${ }^{6}$ Department of Gynecology, Obstetric, and Urology, Sapienza University of Rome, Italy \\ ${ }^{7}$ Centro Riferimento Alcologico Regione Lazio, Sapienza University of Rome, Italy \\ ${ }^{8}$ Department of Pediatrics, Medical Faculty, Sapienza University of Rome, Italy
}

The nerve growth factor (NGF) belongs to a family of proteins termed neurotrophins, consisting of NGF, brain-derived neurotrophic factor (BDNF), neurotrophin-3 (NT-3), NT-4/5 and NT-6. Today, NGF is well recognized to mediate a large number of trophobiological actions resulting in neurotrophic, immunotrophic and/or metabotrophic effects. The pathobiology of neurodegenerative diseases, including Alzheimer disease, psychiatric disorders (e.g. depression and schizophrenia) and brain parasitic infections have in common the effect of altering the brain levels of neurotrophins and in particular NGF. The involvement of NGF and its TrkA receptor in these pathologies and the recent promising results of NGF therapies are presented and discussed. Biomed Rev 2018; 29: 1-16

Key words: NGF, Alzheimer's disease, depression, schizophrenia, parasite, alcohol, autism

Received 30 November 2018, revised 7 December 2018, accepted 8 December 2018.

* Corresponding authors:

Dr. Marco Fiore, PhD, Institute of Cell Biology and Neurobiology, IBCN-CNR Roma, Italy. E-mail: marco.fiore@cnr.it

Dr. Valentina Carito, PhD, Institute of Cell Biology and Neurobiology, IBCN-CNR Roma, Italy.

E-mail: valentina.carito@gmail.com 


\section{INTRODUCTION}

At the end of the nineteenth century, it was envisaged by Santiago Ramon y Cajal but has not been proven that life at the neuronal level requires trophic support. By a rare combination of scientific reasoning and intuition, the proof was obtained by Levi-Montalcini, Viktor Hamburger and Stanley Cohen in the early 1950's in the Washington University in St Louis, MO, United States, where the first cell growth factor, namely nerve growth factor (NGF), was discovered. This was embodied in a conceptual framework of the neurotrophic theory, which reveals a pivotal role of effector cells in the control of neuronal differentiation, survival and function via production of NGF. Today, NGF and its relative molecules collectively designated neurotrophins are well recognized as mediators of multiple biological phenomena in health and disease, ranging from the neurotrophic through immunotrophic to metabotrophic effects. Consequently, NGF is implicated in the pathogenesis of a large spectrum of neuronal disorders (Alzheimer's and other neurodegenerative diseases) and nonneuronal disorders (atherosclerosis, obesity, type 2 diabetes mellitus and other cardiometabolic diseases).

The present review updates and enlarges evidences for the involvement of NGF in both pathogenesis and therapy of various brain diseases (Tabl. 1).

Table 1. Potential role of nerve growth factor in the pathogenesis and therapy of brain diseases

\section{Neurological diseases}

Alzheimer's disease, Mild cognitive impairment, Huntington's disease,

Parkinson's disease,

Parasitic infections, Human immunodeficiency virus-associated dementia, Epilepsy, Down syndrome, Rett syndrome

\section{Psychiatric diseases}

Depression, Schizophrenia, Eating disorders (anorexia nervosa; bulimia nervosa), Autism,

Attention deficit and hyperactivity disorder (ADHD)

\section{NERVE GROWTH FACTOR}

Nerve growth factor (NGF), firstly isolated in 1951, is a neuropeptide that regulates the proliferation and survival of target neurons (1). Nerve growth factor plays a subtle role in several brain pathologies leading to brain cell death and/or neurodegeneration during development or during aging (2-11). Nerve growth factor is synthesized as a 130 $\mathrm{kD}$ precursor (proNGF) that is a complex of three proteins: $\alpha$-NGF, $\beta$-NGF and $\gamma$-NGF the latter acting as a serine protease that cuts the Beta subunit $\mathrm{N}$ terminal producing the 26 $\mathrm{kD}$ mature NGF that is biologically active as a multifunctional signaling molecule (12-14). Nerve growth factor is involved primarily in the growth, survival, and proliferation of sympathetic and sensory neurons that undergo apoptosis in its absence (15-18). It also plays a delicate role in the physiological regulation of other biological structures as the immune and the endocrine systems and the adipose tissue (14,19-23). Nerve growth factor binds two classes of receptors: the tropomyosin-related kinase $\mathrm{A}$ (TrkA), and the low-affinity NGF receptor p75 (LNGFR/p75 $\left.{ }^{\mathrm{NTR}}\right)(12,24$, $25)$. TrkA receptor binding produces the homodimerization of the receptor and the autophosphorylation of the tyrosine residue of the cytoplasmic tail. This site of TrkA phosphorylation is a docking site for the Shc adaptor protein that is in turn phosphorylated starting several intracellular pathways involved in cell survival $(12,26)$. Among them, one involves the activation of the serine/threonine kinase Akt and develops with the recruitment on TrkA receptor complex of a second adaptor protein, the growth factor receptor bound protein 2 (Grb2) and another docking protein, the Grb2-associated Binder1 (GAB1). This complex activates phosphatidylinositol-3 kinase (P13K), that activates Akt. Blocking the activity of $\mathrm{P} 13 \mathrm{~K}$ or Akt provokes the death of sympathetic neurons in culture also in presence of NGF administration, while when both kinases are constitutively expressed neurons can survive without $\operatorname{NGF}(27,28)$.

Another pathway of NGF mediated neuronal survival involves the mitogen-activated protein kinase (MAPK). This pathway leads to activation of the membrane-associated $G$ protein Ras that phosphorylates the serine/threonine kinase Raf. This phosphorylation activates the MAPK cascade that regulates transcription (26). Both of these pathways give rise to phosphorylation of the cyclic AMP response element binding protein (CREB), a transcription factor that translocates into the nucleus, where controls the expression of antiapoptotic genes.

\section{NGF and Alzheimer disease}

Alzheimer disease (AD), the most common form of dementia in the old age, is characterized by early perturbations of synaptic proteins and synaptic functions with the generation of abnormal tau and amyloid proteins. After the release in 
the intracellular space of these abnormal proteins begins the massive deposition of senile plaques (SP) of $\beta$-amyloid (A $\beta$ ) peptide and the aggregations of neurofibrillary tangles (NTF) that originate from hyperphosphorylated tau protein. As a consequence, during the progression of the disease, appears a serious and progressive memory deficit, a massive neuronal loss and a complete deterioration of the brain homeostasis (29-32). The basal forebrain cholinergic neurons innervate the hippocampus and the cerebral cortex, the regions that control memory and attention. These regions are more susceptible to the AD and the first to be involved (33-36).

In the pathophysiological mechanisms of $\mathrm{AD}$, it turned out to be fundamental the protective role of neurotrophic factors, secreted proteins that control differentiation, plasticity, pruning and survival of forebrain cholinergic neurons (FBCN) of the hypothalamus, cortex and hippocampus. Indeed, the signaling of these peptides is seriously altered in the course of the disease (37). Among these neurotrophins the most studied for its role in the AD is NGF, a glycoprotein of three subunits $\alpha, \beta$ and $\gamma$ that is produced as a precursor pro-NGF and is processed intracellularly to mature NGF by the subunit of the protein $(37,38)$.

Nerve growth factor signaling involves three types of receptors expressed in BFCN: the high-affinity tropomyosinrelated kinase A (TrkA), the low-affinity neurotrophin receptor $\left(\mathrm{p} 75^{\mathrm{NTR}}\right)$ and sortilin. NGF binding to its receptor TrkA activates the pathway signaling of cell survival, while in the presence of lower levels of NGF and/or TrkA the precursor form of NGF (pro-NGF) binds to $\mathrm{p} 75^{\mathrm{NTR}}$ and to sortilin provoking an apoptotic signaling that brings to neurodegeneration (39-41).

Nerve growth factor release by cortical and hippocampal neurons is involved in the processing of amyloid precursor protein (APP) to generate the soluble APP that is neuroprotective and a strong inhibitor of the enzyme $\beta$-secretase 1 (BACE1) that controls APP amyloidogenic cleavage (42, 43). Recent studies in animal and cellular models have shown the protective role of NGF against AD induced neurodegeneration. Also, there is evidence that the perturbation of NGF signaling is one of the earliest events in AD onset (44). In a cellular model such as primary hippocampal neurons, the NGF deprivation generates an Alzheimer's like molecular syndrome with the development of $A \beta$-amyloid plaques and aggregations of neurofibrillary tangles (45). Also, an antibody directed to NGF provokes similar phenotypic effects and neuronal deficits in the AD11 mouse model of AD (46).
The protective role of NGF observed in vivo and in vitro is exerted by the modulation of the processing of amyloid precursor protein (APP) $(42,43)$.

Nerve growth factor stimulation of primary cholinergic septal neurons promotes the binding of NGF receptor TrkA to APP. This binding blocks the APP phosphorylation at threonine 668 (T668) residue in the cytosolic tail of the protein. T668 phosphorylation is a post-translational modification of APP that induces APP cleavage by the enzyme BACE1, that controls the amyloidogenic pathway of maturation $(42,43,46)$.

In $\mathrm{AD}$ development, where there is a deficit of NGF, amyloid generation increases and could affect the initial synaptic alteration observed in mild cognitive impairments and early AD. The newly generated amyloid inhibits the endocytosis of NGF/TrkA complex and this negative feedback loop marks the AD onset (29).

In rat models of aging, elevated levels of pro-NGF and p $75^{\mathrm{NTR}}$ in hippocampus and prefrontal cortex are associated with a deficit in spatial recognition and memory (47). An increase in pro-NGF levelss was also observed in mild cognitive impairment and $\mathrm{AD}$ patients and also in postmortem $\mathrm{AD}$ brain examination (44). The perturbation of NGF signaling is an early event during the progression of the $\mathrm{AD}$ as evidenced by the studies on animal and cellular models (30). In animal models of aged rats the blocking of NGF/TrkA signaling provokes a serious deficit of cholinergic function $(48,49)$. In animal models of $\mathrm{AD}$, the alteration of NGF signaling brings to a general loss of central cholinergic function (50). The effect of the imbalance in NGF/TrkA signaling is a pathological APP processing (45). In transgenic mice lacking the APP/ TrkA interaction, it is observed a serious degeneration of cholinergic neurons and cognitive deficits (51). These studies seem to support the hypothesis of the neurotrophic model of $\mathrm{AD}$ development where the reduction of NGF level and the increase of pro-NGF would trigger the synaptic failure and the abnormal amyloid and tau deposition starting a neurodegenerative cascade $(28,52)$.

New pieces of evidence prove that the relationship between NGF and APP processing relies on a physical interaction between APP and NGF receptors (30). The APP juxta-membrane region which contains the $\alpha$ and $\beta$-secretase cutting sites and matches the first 16 aa of $A \beta$ peptide is sufficient for the interaction with TrkA and the binding to p75 ${ }^{\mathrm{NTR}}$ (53). APP and TrkA proteins localize in the plasma membrane, endoplasmic reticulum (ER), Golgi and endocyt- 
ic vesicles where the proteins form homodimers (30).

In primary septal neurons, NGF treatment increases APP/ TrkA complexes in ER and Golgi without increasing the protein level probably because NGF affects the association through the control of APP phosphorylation $(30,43)$. NGF withdrawal induces a decrease of APP/TrkA complexes and the same pattern is observed with cell death inducers such as $A \beta$ peptide, and rapamycin. Furthermore, NGF, favoring APP/TrkA complexes, disadvantages the APP/APP homodimers that are more prone to amyloidogenic processing carried out by $\beta$ and $\gamma$-secretase $(30,43)$.

The APP post-translational modifications are critical for the physiological or amyloidogenic pathway (54). The phosphorylation of threonine residue 668 (T668) is connected to amyloid production, synaptic deficits and apoptosis $(55,56)$. This phosphorylation blocks APP/TrkA binding and increases $\mathrm{A} \beta$ production in cholinergic neurons in vivo and in vitro. A recent finding has shown that NGF can reduce APP T668 level in cultured BFCN. It is possible that the detachment of APP from TrkA is caused by a change in the conformation of APP upon this phosphorylation (43).

In the physiological anti-amyloidogenic pathway, binding of NGF to TrkA induces TrkA phosphorylation and TrkA docking of the signaling adaptor $\mathrm{SH} 2$ containing sequence C (ShcC). Activated ShcC blocks c-Jun N-terminal kinase (JNK), a ser/thr APP kinase, preventing the APP phosphorylation at threonine residue 668 (T668). Since TrkA can bind only APP molecules not phosphorylated at T668, the NGF reduction of APP p668 levels stimulates ATP-TrkA binding, and the TrkA mediated trafficking of APP to the plasma membrane and Golgi apparatus and the preferential cleavage of APP by the neuronal $\alpha$-secretases ADAM10-17. Conversely, reduced availability of mature NGF and/or reduced expression levels of TrkA result in pre-apoptotic signals that activate JNK, increase APP pT668 and disturb APP-TrkA interaction favoring the $\beta$-Secretase 1 amyloidogenic pathway (43).

Beneficial role of NGF on cholinergic neurons is carried out downregulating T668 phosphorylation, stimulating APP/ TrkA binding and trafficking to subcellular compartments, as Golgi complex, that is depleted of the amyloidogenic enzyme like BACE1. Tau pathology is implicated in non-Alzheimer disease pathophysiology (suspected non-Alzheimer disease pathophysiology - SNAP). In AD many studies demonstrated a synergism between tangles and plaques, with abnormal tau that enhances $\mathrm{A} \beta$ toxicity and vice-versa $(57,58)$.
Nerve growth factor can regulate the steady-state levels and the posttranslational maturation of tau that is phosphorylation, cleavage, and ubiquitination $(59,60)$. NGF withdrawal brings to hyperphosphorylation of tau that is Aß-dependent and to abnormal cleavage of the $\mathrm{N}$ terminal fragment of the protein that lacks the microtubule-binding domain. The same tau fragment was also observed in animal AD models with impaired NGF signaling $(59,61)$.

\section{NGF and Schizophrenia}

Growth factors that control pathways involved in normal brain development have an important role in the pathophysiology of mental illness that has also a neurodevelopmental origin. Significant alterations of their levels were observed in patients and also in animal models where altered levels of these proteins induce psychiatric behavior (62).

During the embryonic and postnatal stages, psychophysical stress altering the environment can modify the normal development of the brain opening the way in the adulthood to psychopathologies such as hyper-anxiety, anomalous social behavior, alcohol abuse and drug dependence, schizophrenia, and depression (63-67). In the rat, gestational stress increases maternal and fetal plasma corticosterone with dysregulation of the hypothalamic-pituitary-adrenal (HPA) axis and a prolonged elevation of plasma glucocorticoids in response to stress events $(64,65)$. Synaptic development and neurotransmitter activity are modified by increased activity of corticosterone and corticotrophin-releasing hormone $(\mathrm{CRH})$ in developing brain causing behavioral dysfunctions in adulthood. For example, rats exposed to intrauterine stress develop depressive-like behaviors and hyper-anxiety coupled with the increase of CRH activity in the amygdala $(64,65)$. Interestingly, abnormalities in the HPA axis described in prenatally stressed animals were also reported in humans with endogenous depression (68-70). Also during early postnatal life, the development of the nervous system is sensitive to stress events, and this contributes to inter-individual differences in vulnerability to psychopathology. In the postnatal development of CNS, the neural network undergoes deep rearrangements $(71,72)$ and is particularly sensitive to external stimuli. In this phase, the role of NGF and BDNF is to modulate brain plasticity to better adapt to the environment. As an example, mice grown in a nest with caregiving mothers display better social interaction and skills compared to mice bred in standard laboratory conditions. The socially enriched mice present also higher levels of NGF and BDNF 
in hippocampus and hypothalamus $(73,74)$. In the mouse, NGF is produced and secreted by the submaxillary salivary glands $(75,76)$. Neurobehavioral studies have shown that intraspecific fighting in adult male mice provoked a remarkable release of NGF from salivary glands into the bloodstream. These observations demonstrated a correlation between the serum concentration of NGF and the status achieved in the fighting were the subordinate mice showed double serum levels of NGF compared to dominant mice (77-79). Other studies have confirmed the association between increased NGF levels and subordinate behavior $(80,81)$. In male mice, the chronic administration of NGF reduced aggressive behavior (79). NGF release was activated by psychosocial stress that depends on interspecific interactions while physical stressors have less pronounced effects $(73,74)$. Intermale aggressive behavior increases the synthesis of NGF in the hypothalamus (82) probably because the NGF levels respond to psychological stimuli connected to fear and anxiety and interplay with hormones and neurotransmitters to integrate the neuroendocrine response and the behavior to ensure the physiological homeostasis $(2,14,81)$. Data from humans and animal models suggest a role of neurotrophins also in vulnerability to stress-related neuropsychosis $(83,84)$. Growing literature evidences showed that in psychopathological disease the constitutive levels of neurotrophins are altered in both brain and plasma. In schizophrenic patients, without neuroleptic therapy, the plasma levels of NGF are lower compared to healthy controls (85). Administration of the antipsychotic drug haloperidol in human and mice drastically reduces the plasma levels of NGF (86) inducing sedation. In contrast, the atypical antipsychotics risperidone, clozapine, and olanzapine showed higher levels of plasmatic NGF compared to never-medicated first-episode psychotic patients (87). The critical role of NGF during the development of cholinergic neurons that control learning and memory could explain the vulnerability of schizophrenic brain and the cognitive deficits observed in this disease because the low levels of NGF trigger a consequent neurodevelopmental deficit $(14,88)$. In schizophrenic patients, brain imaging studies showed alteration in brain areas such as prefrontal, temporal and anterior cingulum known to be involved in affective-cognitive integration (89). Also, the schizophrenic brain post-mortem examination showed a reduction of cell proliferation in the entorhinal cortex, anterior cingulate and prefrontal region that could explain the origin of the disease $(85,89)$. In animal models, behavioral deficits that correlate to schizophrenic symptoms (90) develop also by maternal exposure to risk factors such as ethanol and drug abuse that inhibit entorhinal and cortical neurogenesis (91).

Schizophrenia is a multifactorial mental disease triggered by social, genetic and developmental factors (92). Among the genes that have been observed to be involved in this disease one is Disrupted-in-schizophrenia 1 (DISC1) $(93,94)$ which is expressed by neurons of the cerebral cortex, hippocampus, olfactory bulb and cerebellum in rat brain (95-97). The protein binds other proteins including fasciculation and elongation protein zeta-1(Fez1), involved in axonal outgrowth. DISC1Fez1 molecular complex colocalizes in the growth cone of neurite suggesting a role in the process of extension also confirmed by the fact that these proteins are expressed in early ontogenic stages. Studying the neurodifferentiation of PC12 cells stimulated with NGF was observed a drastic increase of Fez1 suggesting that NGF controls the neurite extension and outgrowth upregulating DISC1-Fez1 complex (92). When the DISC1 translocation prevents the complex being formed, neurite extension cannot happen and the brain development remains immature, supporting the hypothesis that schizophrenia is essentially a neurodevelopmental disease (92).

\section{NGF and Major Depression Disorder}

Major depression disorder (MDD) is the most common of brain disorders and involves depression, scarce interest in normal daily activities, fatigue, a decrease in concentration, suicidal intentions (98). Several neurotrophins including NGF and BDNF are involved in MDD pathogenesis (99, 100). Major depression disorder patients present reduced serum NGF, and the same reduction was observed in hippocampus mRNA and protein expression of NGF, BDNF and their receptors in post-mortem examination $(101,102)$. The chemical mediator of NGF reduction is interferon-gamma (IFN- $\gamma$ ), as was observed in IFN- $\gamma$ knockout mice models that develop a depressive-like behavior, an increased immobility and a parallel reduction of NGF levels $(103,104)$.

The administration of NGF in rats decreases the expression of cholinergic gene CHRNA5 and prokineticin receptor1 (PROKR1) miming the effects of fluoxetine and amitriptyline therapy. The improvement of the depression-like behavior is realized by modifying the expression of several genes of amygdala and hippocampus (105).

\section{NGF in Autism Spectrum Disorder}

Autism Spectrum Disorder (ASD) involves deficits in social 
communication and repetitive pattern of behavior. Genetic aberrations play a crucial role in developing ASD with hundreds of genes associated with it, which however do not show to converge in a common molecular pathway. Genetic studies and behavioral observations demonstrate the overlapping of ASD with other psychiatric disorders, such as schizophrenia, bipolar disorder, and Attention Deficit and Hyperactivity Disorder (ADHD) $(106,107)$. In a study of differential alternative splicing (DAS) in the blood of 2-4 years old boys with a diagnosis of ASD, there were significant DAS differences in several genes of NGF receptors and signaling compared to controls (108). Another study of Lu et al showed several SNP NGF associated with deficits in nonverbal communication that is one of the autistic trail (109).

\section{NGF and Alcohol-Induced Mental Retardation}

Several human evidences have shown that chronic or binge alcohol consumption as well as alcohol exposure during development are a main inducing-cause of brain changes (110) and mental retardation in both adults and children (88, 111-119). As for the gestational alcohol consumption, the plethora of effects in children induced by ethanol are described as Fetal Alcohol Spectrum Disorders (120-123). It has also been clearly demonstrated that chronic or binge alcohol consumption as well as alcohol exposure during development may impair brain neurotrophic factors production and the expression of their receptors (124-132). NGF is one of the most important neurotrophins involved in ethanol-induced toxicity. Indeed, NGF and their receptors are known to be altered in the brain during prenatal/ acute/chronic alcohol consumption (133-138). In particular, as previously indicated (133) alcohol inhibits the expression of endogenous extracellular signal-regulated kinase (ERK) and the phosphatidylinositol-3-kinase (PI3K) (139-141). In addition, data disclosed several epigenetic rules of NGF and BDNF, the serum levels of interleukin-6 (IL-6) and tumor necrosis factor- $\alpha(\mathrm{TNF}-\alpha)$ and the symptomatology of alcohol dependence $(142,143)$. In particular, it has been shown an increase in NGF and IL-6 serum levels following alcohol consumption as well as an association between BDNF, TNF- $\alpha$ serum levels and the history of alcohol consumption, suggesting that changes in the methylation of neurotrophins genes may contribute to the development of alcohol dependence by affecting relevant downstream signalling cascades $(133,143)$.

\section{NGF and Brain Parasitosis}

The role of NGF in parasitic disease is not yet clear estab- lished but some clues have emerged from the study on Trypanosoma cruzi and Schistosoma mansoni neuroinflammation of the brain.

Chagas disease or American trypanosomiasis is a tropical parasitic disease caused by the protist Trypanosoma cruzi spread to humans and mammals by the insects "kissing bugs" of the subfamily Triatominae $(144,145)$. During the early stage, symptoms are not present or are mild with fever, headache, swollen lymph nodes. Only $40 \%$ of people develop severe symptoms of the disease after 30-40 years from the infection that include heart failure due to enlargement of heart ventricles, or enlarged esophagus or colon (megaesophagus or megacolon). This disease affects 6,6 million people mostly in Central America and Mexico (146).

Trypanosoma cruzi produces the NGF mimetic neurotrophin called parasite-derived neurotrophic factor (PDNF), a membrane-bound neuraminidase/trans-sialidase that can bind TrkA but not p75 ${ }^{\mathrm{NTR}}(147,148)$.

Trypanosoma infection of CNS is usually asymptomatic and neuronal examination has shown neuroprotection and neurons preservation also near foci of inflammatory cells or parasite nest (149). Neuroprotection and neuroregeneration were also observed in animals with acute or chronic infection (150-153). Signs of sprouting of sympathetic and parasympathetic nerve fibers were observed in heart and colon with increased levels of neurotransmitters $(154,155)$. These data have shown that PDNF is a functional mimic of NGF that can bind TrkA in an NGF inhibitable manner, can induce TrkA autophosphorylation and can trigger Pl3K/Akt and MAPKErk1/2 signaling that promotes cell survival and neurite outgrowth. The inability of binding $\mathrm{p} 75^{\mathrm{NTR}}$ inhibits the celldeath signaling pathway $(156,157)$. Given the critical role of TrkA in neuronal maintenance, the parasitic invader utilizes this receptor to reduce tissue damage, to stimulate protective mechanisms and tissue repair maximizing host-parasite equilibrium in order to prolong parasitism. This mechanism could reflect a general and unexpected model of host-parasite interaction (156).

Neuroschistosomiasis (NS) refers to the Schistosoma mansoni infection of the central nervous system and depends basically on the presence of parasite eggs in the nervous tissue and on the host immune response. After eggs deposition, the mature embryo secretes and excretes antigenic and immunogenic mediators that start the granulomatosis reaction. A large number of eggs and granulomas in CNS regions damage the adjacent tissues by the inflammatory reaction and the mass ef- 
fect (158-162). In infected mice that manifest granulomas in several CNS regions it is observed an increase in NGF levels in the cortex, hypothalamus, and brain stem with paw hyperalgesia $(163,164)$. This murine model of chronic infection suggests that the neuropathological and sensory deficits observed in human infection are associated with abnormal NGF levels and/or activity in peripheral and central nervous system caused by the local formation of granulomas (75,165-171).

\section{NGF-based Therapy}

The protective effect of NGF in animal models of neurodegenerative disease has led to clinical trials of NGF therapy in humans for several brain diseases including $\mathrm{AD}$, schizophrenia $(172,173)$ and hopefully for other brain pathologies.

Encouraging results were observed in patients' basal forebrain in which were implanted connective cells engineered to synthesize and secrete NGF. In these experiments were observed enhanced cell size and new formation of neural fibers. Also, the cell showing signs of pathology and protein clumps inside the cell body maintained a healthy size, activated prosurvival signaling and manifested stress resistance. To prolong the expression of NGF, modified viruses that contain the NGF gene were directly injected in the basal forebrain $(174,175)$. The protective role of NGF and its progressive decrease in $\mathrm{AD}$ is the rationale of NGF therapy in which the administration of exogenous NGF could antagonize the basal forebrain neurodegeneration. The first promising results were obtained in rodents where intracerebral NGF delivery was neuroprotective for cholinergic neurons. Also in AD models like APP/PSI transgenic mouse, the less invasive ocular or nasal administration of NGF reduces beta-amyloid deposition (176). In AD patients NGF gene therapy in phase I has shown axonal sprouting without side effects (176).

Anomalies in the levels of NGF or NGF signaling and the resulting impairment of neuroplasticity and cognitive functions were also observed in psychiatric disorders such as schizophrenia, depression, bipolar disorders, alcohol use disorders and autism. In schizophrenic patients in therapy with atypical antipsychotic drugs, NGF levels increase leading to a reduction of negative symptoms $(49,177)$. In bipolar disorders, NGF decreases during the manic state and is rescued by lithium administration that increases the NGF concentration in the frontal cortex, hippocampus, and amygdala (178). In children with Rett syndrome, a condition that causes a delay in development and cognitive disability resembling autism, therapies with NGF-like activity drugs improve motor and cortical functions and increase social interactions (179).

\section{CONCLUSIONS}

Many years of research have well documented the important trophic and homeostatic role of NGF that exerts its modulatory activities on nervous, endocrine, adipose and immune system functions. Future researches, through a greater knowledge of the mechanism of action of this small and versatile peptide, will help to develop updated brain therapeutic strategies for many clinical areas including those involving neuroinflammation, neurodegeneration and neuroadipocrinology $(2,20,23,180,181)$.

\section{CONFLICT OF INTEREST STATEMENT}

The authors certify that they have no affiliations with or involvement in any organization with any financial interest in the subject matter discussed in this review article.

\section{ACKNOWLEDGEMENTS}

We apologize to the authors of many relevant articles that were not quoted here for reasons of brevity.

\section{REFERENCES}

1. Levi-Montalcini R. The nerve growth factor 35 years later. Science 1987; 237:1154-1162. DOI:10.1126/science.3306916

2. Yanev, Stanislav, Aloe L, Fiore M, Chaldakov GN. Neurotrophic and metabotrophic potential of nerve growth factor and brain-derived neurotrophic factor: Linking cardiometabolic and neuropsychiatric diseases. World $J$ Pharmacol 2013; 2:92. DOI:10.5497/wjp.v2.i4.92

3. Greco A, Ralli M, De Virgilio A, Inghilleri M, Fusconi M, de Vincentiis M. Letter to the Editor: Autoimmune pathogenic mechanisms in Huntington's disease. $A u$ toimmun Rev 2018; 17:942-943. DOI:10.1016/j.autrev.2018.04.003

4. Hillis J, O’Dwyer M, Gorman AM. Neurotrophins and B-cell malignancies. Cell Mol Life Sci 2016; 73:41-56. DOI:10.1007/s00018-015-2046-4

5. Skaper SD. Nerve growth factor: a neuroimmune crosstalk mediator for all seasons. Immunology 2017; 151:1-15. DOI:10.1111/imm.12717

6. Pepeu G, Grazia Giovannini M. The fate of the brain cholinergic neurons in neurodegenerative diseases. Brain Res 2017; 1670:173-184. DOI:10.1016/j.brainres.2017.06.023 
7. Aygun N. Biological and genetic features of neuroblastoma and their clinical importance. Curr Pediatr Rev 2018; 14:73-90. DOI:10.2174/1573396314666180129 101627

8. Fields J, Dumaop W, Langford TD, Rockenstein E, Masliah E. Role of neurotrophic factor alterations in the neurodegenerative process in HIV associated neurocognitive disorders. J Neuroimmune Pharmacol 2014; 9:102-116. DOI:10.1007/s11481-013-9520-2

9. Allen SJ, Watson JJ, Shoemark DK, Barua NU, Patel NK. GDNF, NGF and BDNF as therapeutic options for neurodegeneration. Pharmacol Ther 2013; 138:155-175. DOI:10.1016/j.pharmthera.2013.01.004

10. Iulita MF, Caraci F, Cuello AC. A link between nerve growth factor metabolic deregulation and amyloid-betadriven inflammation in Down syndrome. CNS Neurol Disord Drug Targets 2016; 15:434-447.

11. Greco A, Ralli M, Inghilleri M, De Virgilio A, Gallo A, de Vincentiis M. Letter to the Editor: Autoimmune pathogenic mechanisms in amyotrophic lateral sclerosis. Autoimmun Rev 2018; 17:530-531. DOI:10.1016/j. autrev.2018.04.003

12. Kaplan DR, Martin-Zanca D, Parada LF. Tyrosine phosphorylation and tyrosine kinase activity of the trk proto-oncogene product induced by NGF. Nature 1991; 350:158-160. DOI:10.1038/350158a0

13. Donovan MJ, Miranda RC, Kraemer R, McCaffrey TA, Tessarollo L, Mahadeo D, et al. Neurotrophin and neurotrophin receptors in vascular smooth muscle cells. Regulation of expression in response to injury. Am J Pathol 1995; 147:309-324.

14. Fiore M, Chaldakov GN, Aloe L. Nerve growth factor as a signaling molecule for nerve cells and also for the neuroendocrine-immune systems. Rev Neurosci 2009; 20:133-145. DOI:10.1515/REVNEURO.2009.20.2.133

15. Carito V, Venditti A, Bianco A, Ceccanti M, Serrilli AM, Chaldakov G, et al. Effects of olive leaf polyphenols on male mouse brain NGF, BDNF and their receptors TrkA, TrkB and p75. Nat Prod Res 2014; 28:1970-1984. DOI $: 10.1080 / 14786419.2014 .918977$

16. De Nicoló S, Tarani L, Ceccanti M, Maldini M, Natella F, Vania A, et al. Effects of olive polyphenols administration on nerve growth factor and brain-derived neurotrophic factor in the mouse brain. Nutrition 2013; 29:681-687. DOI:10.1016/j.nut.2012.11.007

17. van der Laan BF, Freeman JL, Asa SL. Expression of growth factors and growth factor receptors in normal and tumorous human thyroid tissues. Thyroid 1995; 5:67-73.

18. Freeman RS, Burch RL, Crowder RJ, Lomb DJ, Schoell MC, Straub JA, et al. NGF deprivation-induced gene expression: after ten years, where do we stand? Prog Brain Res 2004; 146:111-126. DOI:10.1016/S00796123(03)46008-1

19. Chaldakov GN, Beltowsky J, Ghenev PI, Fiore M, Panayotov P, Rančič G, et al. Adipoparacrinology - vascular periadventitial adipose tissue (tunica adiposa) as an example. Cell Biol Int 2012; 36:327-330. DOI:10.1029/2011JD017014

20. Chaldakov GN, Fiore M, Tonchev AB, Dimitrov D, Pancheva R, Rancic G, et al. Homo obesus: A metabotrophin-deficient species. Pharmacology and nutrition insight. Curr Pharm Des 2007; 13:2176-2179. DOI:10.2174/138161207781039616

21. Chaldakov GN, Fiore M, Ghenev PI, Stankulov IS, Aloe L. Atherosclerotic lesions: Possible interactive involvement of intima, adventitia and associated adipose tissue. Int Med J 2000; 7:43-49.

22. Tore F, Tonchev A, Fiore M, Tuncel N, Atanassova $\mathrm{P}$, Aloe L, et al. From adipose tissue protein secretion to adipopharmacology of disease. Immunol Endocr Metab Agents Med Chem 2007; 7:149-155. DOI:10.2174/187152207780363712

23. Chaldakov GN, Fiore M, Tonchev AB, Aloe L. Neuroadipology: A novel component of neuroendocrinology. Cell Biol Int 2010; 34:1051-1053. DOI:10.1042/ CBI20100509

24. Levi-Montalcini R. The nerve growth factor: 35 years later (Nobel Lecture). Angew Chemie Int Ed English 1987; 26:707-716. DOI:10.1002/anie.198707073

25. Chao M V. Trophic factors: An evolutionary cul-de-sac or door into higher neuronal function? J Neurosci Res 2000; 59:353-355.

26. Sanes DH, Reh TA, Harris WA. Development of the nervous system. Elsevier 2005.

27. Yano H, Chao M V. Neurotrophin receptor structure and interactions. Pharm Acta Helv 2000; 74:253-260. DOI:10.1016/S0031-6865(99)00036-9

28. Niewiadomska G, Mietelska-Porowska A, Mazurkiewicz $M$. The cholinergic system, nerve growth factor and the cytoskeleton. Behav Brain Res 2011); 221:515-526. DOI:10.1016/j.bbr.2010.02.024 
29. Xu C-J, Wang J-L, Jin W-L. The Emerging Therapeutic Role of NGF in Alzheimer's Disease. Neurochem Res 2016; 41:1211-1218. DOI:10.1007/s11064-016-1829-9

30. Canu N, Amadoro G, Triaca V, Latina V, Sposato V, Corsetti $\mathrm{V}$, et al. The Intersection of NGF/TrkA Signaling and Amyloid Precursor Protein Processing in Alzheimer's Disease Neuropathology. Int J Mol Sci 2017; 18: DOI: $10.3390 / \mathrm{ijms} 18061319$

31. Angelucci F, Gelfo F, Fiore M, Croce N, Mathé AA, Bernardini S, et al. The effect of neuropeptide $\mathrm{Y}$ on cell survival and neurotrophin expression in in-vitro models of Alzheimer's disease. Can J Physiol Pharmacol 2014; 92:621-630. DOI:10.1139/cjpp-2014-0099

32. Scott SA, Mufson EJ, Weingartner JA, Skau KA, Crutcher KA. Nerve growth factor in Alzheimer's disease: increased levels throughout the brain coupled with declines in nucleus basalis. J Neurosci 1995; 15:6213-21.

33. Arendt T. Impairment in memory function and neurodegenerative changes in the cholinergic basal forebrain system induced by chronic intake of ethanol. Cell Anim Model Aging Dement Res 1994; 44:173-187. DOI:10.1007/978-3-7091-9350-1_13

34. Arendt T, Bruckner MK, Bigl V, Marcova L. Dendritic reorganisation in the basal forebrain under degenerative conditions and its defects in Alzheimer's disease. III. The basal forebrain compared with other subcortical areas. J Comp Neurol 1995; 351:223-246. DOI:10.1002/ cne. 903510204

35. Arendt T, Marcova L, Bigl V, Bruckner MK. Dendritic reorganisation in the basal forebrain under degenerative conditions and its defects in Alzheimer's disease. I. Dendritic organisation of the normal human basal forebrain. J Comp Neurol 1995; 351:169-188. DOI:10.1002/ cne. 903510202

36. Arendt T, Bruckner MK, Bigl V, Marcova L. Dendritic reorganisation in the basal forebrain under degenerative conditions and its defects in Alzheimer's disease. II. Ageing, Korsakoff's disease, Parkinson's disease, and Alzheimer's disease. J Comp Neurol 1995; 351:189-222. DOI:10.1002/cne.903510203

37. Skaper SD. Neurotrophic factors: An overview. Methods Mol Biol 2018; 1727:1-17. DOI:10.1007/978-1-49397571-6_1

38. Budni J, Bellettini-Santos T, Mina F, Garcez ML, Zugno AI. The involvement of BDNF, NGF and GDNF in aging and Alzheimer's disease. Aging Dis 2015; 6:331-341.
DOI:10.14336/AD.2015.0825

39. Huang EJ, Reichardt LF. Trk receptors: Roles in neuronal signal transduction. Аппи Rev Biochem 2003; 72:609642. DOI:10.1146/annurev.biochem.72.121801.161629

40. Guerios SD, Wang Z-Y, Boldon K, Bushman W, Bjorling DE. Blockade of NGF and trk receptors inhibits increased peripheral mechanical sensitivity accompanying cystitis in rats. AJP Regul Integr Comp Physiol 2008; 295:R111R122. DOI:10.1152/ajpregu.00728.2007

41. Chao M V., Hempstead BL. p75 and Trk: A tworeceptor system. Trends Neurosci 1995; 18:321-326. DOI:10.1016/0166-2236(95)93922-K

42. Triaca V. Homage to Rita Levi-Montalcini. Molecular mechanisms of Alzheimer's disease: NGF modulation of APP processing. Adipobiology 2013; 5:7-18. DOI:10.14748/adipo.v5.292

43. Triaca V, Sposato V, Bolasco G, Ciotti MT, Pelicci P, Bruni AC, et al. NGF controls APP cleavage by downregulating APP phosphorylation at Thr668: relevance for Alzheimer's disease. Aging Cell 2016; 15:661-672. DOI:10.1111/acel.12473

44. Mufson EJ, He B, Nadeem M, Perez SE, Counts SE, Leurgans $\mathrm{S}$, et al. Hippocampal proNGF signaling pathways and beta-amyloid levels in mild cognitive impairment and Alzheimer disease. J Neuropathol Exp Neurol 2012; 71:1018-1029. DOI:10.1097/ NEN.0b013e318272caab

45. Calissano P, Matrone C, Amadoro G. Nerve growth factor as a paradigm of neurotrophins related to Alzheimer's disease. Dev Neurobiol 2010; 70:372-383. DOI:10.1002/ dneu.20759

46. Ruberti F, Capsoni S, Comparini A, Di Daniel E, Franzot $\mathrm{J}$, Gonfloni S, et al. Phenotypic knockout of nerve growth factor in adult transgenic mice reveals severe deficits in basal forebrain cholinergic neurons, cell death in the spleen, and skeletal muscle dystrophy. J Neurosci 2000; 20:2589-2601.

47. Terry AVJ, Kutiyanawalla A, Pillai A. Age-dependent alterations in nerve growth factor (NGF)-related proteins, sortilin, and learning and memory in rats. Physiol Behav 2011; 102:149-157. DOI:10.1016/j. physbeh.2010.11.005

48. Yegla B, Parikh V. Effects of sustained proNGF blockade on attentional capacities in aged rats with compromised cholinergic system. Neuroscience 2014; 261:118-132. DOI:10.1016/j.neuroscience.2013.12.042 
49. Parikh V, Howe WM, Welchko RM, Naughton SX, D'Amore DE, Han DH, et al. Diminished trkA receptor signaling reveals cholinergic-attentional vulnerability of aging. Eur J Neurosci 2013; 37:278-293. DOI:10.1111/ ejn. 12090

50. Counts SE, Mufson EJ. The role of nerve growth factor receptors in cholinergic basal forebrain degeneration in prodromal Alzheimer disease. J Neuropathol Exp Neurol 2005; 64:263-272.

51. Matrone C, Di Luzio A, Meli G, D’Aguanno S, Severini C, Ciotti MT, et al. Activation of the amyloidogenic route by NGF deprivation induces apoptotic death in PC12 cells. J Alzheimers Dis 2008; 13:81-96.

52. Latina V, Caioli S, Zona C, Ciotti MT, Amadoro G, Calissano P. Impaired NGF/TrkA signaling causes early ADlinked presynaptic dysfunction in cholinergic primary neurons. Front Cell Neurosci 2017; 11:68. DOI:10.3389/ fncel.2017.00068

53. O’Brien RJ, Wong PC. Amyloid precursor protein processing and Alzheimer's disease. Annu Rev Neurosci 2011; 34:185-204. DOI:10.1146/annurev-neuro-061010-113613

54. Tamayev R, Zhou D, D'Adamio L. The interactome of the amyloid beta precursor protein family members is shaped by phosphorylation of their intracellular domains. Mol Neurodegener (2009) 4:28. DOI:10.1186/1750-1326-428

55. Lee M-S, Kao S-C, Lemere CA, Xia W, Tseng H-C, Zhou $\mathrm{Y}$, et al. APP processing is regulated by cytoplasmic phosphorylation. J Cell Biol 2003; 163:83-95. DOI:10.1083/ jcb. 200301115

56. Chang K-A, Kim H-S, Ha T-Y, Ha J-W, Shin KY, Jeong $\mathrm{YH}$, et al. Phosphorylation of amyloid precursor protein (APP) at Thr668 regulates the nuclear translocation of the APP intracellular domain and induces neurodegeneration. Mol Cell Biol 2006; 26:4327-4338. DOI:10.1128/ MCB.02393-05

57. Bloom GS. Amyloid-beta and tau: the trigger and bullet in Alzheimer disease pathogenesis. JAMA Neurol 2014; 71:505-508. DOI:10.1001/jamaneurol.2013.5847

58. Ribe EM, Perez M, Puig B, Gich I, Lim F, Cuadrado M, et al. Accelerated amyloid deposition, neurofibrillary degeneration and neuronal loss in double mutant APP/ tau transgenic mice. Neurobiol Dis 2005; 20:814-822. DOI:10.1016/j.nbd.2005.05.027

59. Amadoro G, Corsetti V, Ciotti MT, Florenzano F, Capsoni $\mathrm{S}$, Amato G, et al. Endogenous Abeta causes cell death via early tau hyperphosphorylation. Neurobiol Aging 2011; 32:969-990. DOI:10.1016/j.neurobiolaging.2009.06.005

60. Carter C. Alzheimer's disease: APP, gamma secretase, APOE, CLU, CR1, PICALM, ABCA7, BIN1, CD2AP, CD33, EPHA1, and MS4A2, and their relationships with herpes simplex, C. Pneumoniae, other suspect pathogens, and the immune system. Int J Alzheimers Dis 2011; 2011:501862. DOI:10.4061/2011/501862

61. Corsetti V, Amadoro G, Gentile A, Capsoni S, Ciotti MT, Cencioni MT, et al. Identification of a caspase-derived Nterminal tau fragment in cellular and animal Alzheimer's disease models. Mol Cell Neurosci 2008; 38:381-392. DOI:10.1016/j.mcn.2008.03.011

62. Galvez-Contreras AY, Campos-Ordonez T, Lopez-Virgen V, Gomez-Plascencia J, Ramos-Zuniga R, et al. Growth factors as clinical biomarkers of prognosis and diagnosis in psychiatric disorders. Cytokine Growth Factor Rev 2016; 32:85-96. DOI:10.1016/j.cytogfr.2016.08.004

63. Dell'Omo G, Fiore M, Alleva E. Strain differences in mouse response to odours of predators. Behav Processes 1994; 32:105-115. DOI:10.1016/0376-6357(94)90069-8

64. Weinstock M. Prenatal stressors in rodents: Effects on behavior. Neurobiol Stress 2017; 6:3-13. DOI:10.1016/j. ynstr.2016.08.004

65. Weinstock M. Alterations induced by gestational stress in brain morphology and behaviour of the offspring. Prog Neurobiol 2001; 65:427-451. DOI:10.1016/S03010082(01)00018-1

66. Maccari S, Darnaudery M, Morley-Fletcher S, Zuena AR, Cinque C, Van Reeth O. Prenatal stress and long-term consequences: Implications of glucocorticoid hormones. Neurosci Biobehav Rev 2003; 27:119-127. DOI:10.1016/ S0149-7634(03)00014-9

67. Pike IL. Maternal stress and fetal responses: evolutionary perspectives on preterm delivery. Am J Hum Biol 2005; 17:55-65. DOI:10.1002/ajhb.20093

68. Oyola MG, Handa RJ. Hypothalamic-pituitary-adrenal and hypothalamic-pituitary-gonadal axes: sex differences in regulation of stress responsivity. Stress 2017; 20:476-494. DOI:10.1080/10253890.2017.1369523

69. Gaffey AE, Bergeman CS, Clark LA, Wirth MM. Aging and the HPA axis: Stress and resilience in older adults. Neurosci Biobehav Rev 2016; 68:928-945. DOI:10.1016/j.neubiorev.2016.05.036

70. Juruena MF. Early-life stress and HPA axis trigger recurrent adulthood depression. Epilepsy Behav 2014; 38:148-159. DOI:10.1016/j.yebeh.2013.10.020 
71. Guest MA, Its AR, Lin CS. Isomonodromy aspects of the $\mathrm{tt} *$ equations of cecotti and vafa I. Stokes Data. Int Math Res Not 2015; 2015:11745-11784. DOI:10.1093/imrn/ rnu250

72. Hua JY, Smith SJ. Neural activity and the dynamics of central nervous system development. Nat Neurosci 2004; 7:327-332. DOI:10.1038/nn1218

73. Branchi I, D’Andrea I, Sietzema J, Fiore M, Di Fausto V, Aloe L, et al. Early social enrichment augments adult hippocampal BDNF levels and survival of BRDU-positive cells while increasing anxiety- and "depression"-like behavior. J Neurosci Res 2006; DOI:10.1002/jnr.20789

74. Branchi I, D’Andrea I, Fiore M, Di Fausto V, Aloe L, Alleva E. Early social enrichment shapes social behavior and nerve growth factor and brain-derived neurotrophic factor levels in the adult mouse brain. Biol Psychiatry 2006; DOI:10.1016/j.biopsych.2006.01.005

75. Fiore M, Moroni R, Aloe L. Removal of the submaxillary salivary glands and infection with the trematode Schistosoma mansoni alters exploratory behavior and pain thresholds in female mice. Physiol Behav 1997; 62:399-406. DOI:10.1016/S0031-9384(97)00036-X

76. Aloe L, Fiore M. Submandibular glands, nerve growth factor and neuroinflammatory responses in rodents. $B i$ omed Rev 1998; 9:93-99. DOI:10.14748/bmr.v9.139

77. Fiore M, Amendola T, Triaca V, Alleva E, Aloe L. Fighting in the aged male mouse increases the expression of TrkA and TrkB in the subventricular zone and in the hippocampus. Behav Brain Res 2005; DOI:10.1016/j. bbr.2004.08.024

78. Maestripieri D, De Simone R, Aloe L, Alleva E. Social status and nerve growth factor serum levels after agonistic encounters in mice. Physiol Behav 1990; 47:161-164. DOI:10.1016/0031-9384(90)90056-A

79. Bigi S, Maestripieri D, Aloe L, Alleva E. NGF decreases isolation-induced aggressive behavior, while increasing adrenal volume, in adult male mice. Physiol Behav 1992; 51:337-343. DOI:10.1016/0031-9384(92)90150-Z

80. Fiore M, Amendola T, Triaca V, Tirassa P, Alleva E, Aloe L. Agonistic encounters in aged male mouse potentiate the expression of endogenous brain NGF and BDNF: Possible implication for brain progenitor cells' activation. Eur J Neurosci 2003; 17:1455-1464. DOI: 10.1046/j.14609568.2003.02573.x

81. Aloe L, Alleva E, Fiore M. Stress and nerve growth factor: Findings in animal models and humans. Pharmacol
Biochem Behav 2002; 73:159-166. DOI: 10.1016/S00913057(02)00757-8

82. Spillantini MG, Aloe L, Alleva E, De Simone R, Goedert M, Levi-Montalcini R. Nerve Growth-Factor MessengerRNA and Protein Increase in Hypothalamus in A Mouse Model of Aggression. Proc Natl Acad Sci USA 1989; 86:8555-8559. DOI:10.1073/pnas.86.21.8555

83. Bersani G, Iannitelli A, Fiore M, Angelucci F, Aloe L. Data and hypotheses on the role of nerve growth factor and other neurotrophins in psychiatric disorders. Med Hypotheses 2000; 55:199-207. DOI:10.1054/ mehy.1999.1044

84. Stampachiacchiere B, Marinova T, Velikova K, Philipov $\mathrm{S}$, Stankulov IS, Chaldakov GN, et al. Altered levels of nerve growth factor in the thymus of subjects with myasthenia gravis. J Neuroimmunol 2004; 146:199-202. DOI:10.1016/j.jneuroim.2003.10.048

85. Fiore M, Angelucci F, Aloe L, Iannitelli A, Korf J. Nerve growth factor and brain-derived neurotrophic factor in schizophrenia and depression: Findings in humans, and animal models. Curr Neuropharmacol 2003; 1:109-123. DOI:10.2174/1570159033477206

86. Aloe L, Iannitelli A, Bersani G, Alleva E, Angelucci F, Maselli P, et al. Haloperidol administration in humans lowers plasma nerve growth factor level: Evidence that sedation induces opposite effects to arousal. Neuropsychobiology 1997; 36:65-68. DOI:10.1159/000119364

87. Parikh V, Khan MM, Terry A, Mahadik SP. Differential effects of typical and atypical antipsychotics on nerve growth factor and choline acetyltransferase expression in the cortex and nucleus basalis of rats. $J$ Psychiatr Res 2004; 38:521-529. DOI:10.1016/j.jpsychires.2004.03.008

88. Ciafrè S, Fiore M, Ceccanti M, Messina MP, Tirassa $P$, Carito V. Role of neuropeptide tyrosine (NPY) in ethanol addiction. Biomed Rev 2016; 27:27-39. DOI:10.14748/ bmr.v27.2110

89. Raedler TJ, Knable MB, Weinberger DR. Schizophrenia as a developmental disorder of the cerebral cortex. Curr Opin Neurobiol 1998; 8:157-161. DOI:10.1016/S09594388(98)80019-6

90. Fiore M, Dell'Omo G, Alleva E, Lipp HP. A comparison of behavioural effects of prenatally administered oxazepam in mice exposed to open-fields in the laboratory and the real world. Psychopharmacology (Berl) 1995; 122:72-77. DOI:10.1007/BF02246444 
91. Alleva E, Francia N. Psychiatric vulnerability: suggestions from animal models and role of neurotrophins. $\mathrm{Neu}$ rosci Biobehav Rev 2009; 33:525-536. DOI:10.1016/j. neubiorev.2008.09.004

92. Matsuzaki S, Tohyama M. Molecular mechanism of schizophrenia with reference to disrupted-in-schizophrenia 1 (DISC1). Neurochem Int 2007; 51:165-172. DOI:10.1016/j.neuint.2007.06.018

93. Mackie S, Millar JK, Porteous DJ. Role of DISC1 in neural development and schizophrenia. Curr Opin Neurobiol 2007; 17:95-102. DOI:10.1016/j.conb.2007.01.007

94. Millar JK, James K, Brandon NJ, Thomson PA. DISC1 and DISC2: Discovering and dissecting molecular mechanisms underlying psychiatric illness. Ann Med 2004; 36:367-378. DOI:10.1080/07853890410033603

95. Tomoda T, Hikida T, Sakurai T. Role of DISC1 in neuronal trafficking and its tmplication in neuropsychiatric manifestation and neurotherapeutics. Neurotherapeutics 2017; 14:623-629. DOI:10.1007/s13311-017-0556-5

96. Dahoun T, Trossbach S V, Brandon NJ, Korth C, Howes OD. The impact of Disrupted-in-Schizophrenia 1 (DISC1) on the dopaminergic system: a systematic review. Transl Psychiatry 2017; 7:e1015. DOI:10.1038/ tp.2016.282

97. Devine MJ, Norkett R, Kittler JT. DISC1 is a coordinator of intracellular trafficking to shape neuronal development and connectivity. J Physiol 2016; 594:5459-5469. DOI:10.1113/JP272187

98. Iwabuchi SJ, Peng D, Fang Y, Jiang K, Liddle EB, Liddle $\mathrm{PF}$, et al. Alterations in effective connectivity anchored on the insula in major depressive disorder. Eur Neuropsychopharmacol 2014; 24:1784-1792. DOI:10.1016/j. euroneuro.2014.08.005

99. Tanti A, Belzung C. Neurogenesis along the septo-temporal axis of the hippocampus: are depression and the action of antidepressants region-specific? Neuroscience 2013; 252:234-252. DOI:10.1016/j.neuroscience.2013.08.017

100. Lang UE, Borgwardt S. Molecular mechanisms of depression: perspectives on new treatment strategies. Cell Physiol Biochem 2013; 31:761-777. DOI:10.1159/000350094

101. Wiener CD, de Mello Ferreira S, Pedrotti Moreira F, Bittencourt G, de Oliveira JF, Lopez Molina M, et al. Serum levels of nerve growth factor (NGF) in patients with major depression disorder and suicide risk. J Affect Disord 2015; 184:245-248. DOI:10.1016/j.jad.2015.05.067

102. Banerjee R, Ghosh AK, Ghosh B, Bhattacharyya S, Mondal AC. Decreased mRNA and protein expression of BDNF, NGF, and their receptors in the hippocampus from suicide: An analysis in human postmortem brain. Clin Med Insights Pathol 2013; 6:1-11. DOI:10.4137/ CMPath.S12530

103. Mandolesi G, Bullitta S, Fresegna D, Gentile A, De Vito $\mathrm{F}$, Dolcetti E, et al. Interferon-gamma causes mood abnormalities by altering cannabinoid CB1 receptor function in the mouse striatum. Neurobiol Dis 2017; 108:45-53. DOI:10.1016/j.nbd.2017.07.019

104. Campos AC, Vaz GN, Saito VM, Teixeira AL. Further evidence for the role of interferon-gamma on anxiety- and depressive-like behaviors: involvement of hippocampal neurogenesis and NGF production. Neurosci Lett 2014; 578:100-105. DOI:10.1016/j.neulet.2014.06.039

105. McGeary JE, Gurel V, Knopik VS, Spaulding J, McMichael J. Effects of nerve growth factor (NGF), fluoxetine, and amitriptyline on gene expression profiles in rat brain. Neuropeptides 2011; 45:317-322. DOI:10.1016/j. npep.2011.06.002

106. Taurines R, Schwenck C, Westerwald E, Sachse M, Siniatchkin M, Freitag C. ADHD and autism: differential diagnosis or overlapping traits? A selective review. Atten Defic Hyperact Disord 2012; 4:115-139. DOI:10.1007/ s12402-012-0086-2

107. Khanzada NS, Butler MG, Manzardo AM. Gene analytics pathway: Analysis and genetic overlap among Autism Spectrum Disorder, Bipolar Disorder and Schizophrenia. Int J Mol Sci 2017; 18: DOI:10.3390/ijms18030527

108. Stamova BS, Tian Y, Nordahl CW, Shen MD, Rogers S, Amaral DG, et al. Evidence for differential alternative splicing in blood of young boys with autism spectrum disorders. Mol Autism 2013; 4:30. DOI:10.1186/20402392-4-30

109. Lu AT-H, Yoon J, Geschwind DH, Cantor RM. QTL replication and targeted association highlight the nerve growth factor gene for nonverbal communication deficits in autism spectrum disorders. Mol Psychiatry 2013; 18:226-235. DOI:10.1038/mp.2011.155

110. Ceccanti M, Inghilleri M, Attilia ML, Raccah R, Fiore M, Zangen A, et al. Deep TMS on alcoholics: effects on cortisolemia and dopamine pathway modulation. A pilot study. Can J Physiol Pharmacol 2015; 93:283-290. DOI:10.1139/cjpp-2014-0188

111. Ciafrè S, Carito V, Tirassa P, Ferraguti G, Attilia ML, Ciolli $\mathrm{P}$, et al. Ethanol consumption and innate neuroimmunity. Biomed Rev 2017; 28:49-61. DOI:10.14748/bmr. v28.4451 
112. Ciafrè S, Carito V, Ferraguti G, Greco A, Chaldakov GN, Fiore M, Ceccanti M. How alcohol drinking affects our genes: an epigenetic point of view. Biochem Cell Biol 2018; bcb-2018-0248. DOI:10.1139/bcb2018-0248

113. Ledda R, Battagliese G, Attilia F, Rotondo C, Pisciotta F, Gencarelli S, et al. Drop-out, relapse and abstinence in a cohort of alcoholic people under detoxification. Physiol Behav 2019; 198:67-75. DOI:10.1016/j.physbeh.2018.10.009

114. Ceccanti M, Iannitelli A, Fiore M. Italian Guidelines for the treatment of alcohol dependence. Riv Psichiatr 2018; 53:105-106. DOI:10.1708/2925.29410

115. Ceccanti M, Coriale G, Hamilton DA, Carito V, Coccurello R, Scalese B, et al. Virtual Morris task responses in individuals in an abstinence phase from alcohol. Can J Physiol Pharmacol 2018; 96:128-136. DOI:10.1139/ cjpp-2017-0013

116. Ceccanti M, Hamilton D, Coriale G, Carito V, Aloe L, Chaldakov G, et al. Spatial learning in men undergoing alcohol detoxification. Physiol Behav 2015; 149:324-330. DOI:10.1016/j.physbeh.2015.06.034

117. Fein G, Torres J, Price LJ, Di Sclafani V. Cognitive performance in long-term abstinent alcoholic individuals. Alcohol Clin Exp Res 2006; 30:1538-1544. DOI:10.1111/j.1530-0277.2006.00185.x

118. Bernardin F, Maheut-Bosser A, Paille F. Cognitive impairments in alcohol-dependent subjects. Front Psychiatry 2014; 5:78. DOI:10.3389/fpsyt.2014.00078

119. Green CR, Mihic AM, Nikkel SM, Stade BC, Rasmussen C, Munoz DP, et al. Executive function deficits in children with fetal alcohol spectrum disorders (FASD) measured using the Cambridge Neuropsychological Tests Automated Battery (CANTAB). J Child Psychol Psychiatry Allied Discip 2009; 50:688-697. DOI:10.1111/j.1469-7610.2008.01990.x

120. Ferraguti G, Ciolli P, Carito V, Battagliese G, Mancinelli R, Ciafrè $\mathrm{S}$, et al. Ethylglucuronide in the urine as a marker of alcohol consumption during pregnancy: Comparison with four alcohol screening questionnaires. Toxicol Lett 2017; 275:49-56. DOI:10.1016/j. toxlet.2017.04.016

121. Sakata-Haga H, Fukui Y. Effects of ethanol on the development of circadian time keeping system. Nihon Arukoru Yakubutsu Igakkai Zasshi 2007; 42:67-75.

122. del Campo M, Jones KL. A review of the physical features of the fetal alcohol spectrum disorders.
Eur J Med Genet 2017; 60:55-64. DOI:10.1016/j. ejmg.2016.10.004

123. Kodituwakku P, Coriale G, Fiorentino D, Aragón AS, Kalberg WO, Buckley D, et al. Neurobehavioral characteristics of children with fetal alcohol spectrum disorders in communities from Italy: Preliminary results. Alcohol Clin Exp Res 2006;30:1551-1561. DOI:10.1111/j.15300277.2006.00187.x

124. Aloe L, Tuveri MA, Guerra G, Pinna L, Tirassa P, Micera A, et al. Changes in human plasma nerve growth factor level after chronic alcohol consumption and withdrawal. Alcohol Exp Res 1996; 20:462-465. DOI:10.1111/j.1530-0277.1996.tb01076.x

125. Carito V, Ceccanti M, Cestari V, Natella F, Bello C, Coccurello R, et al. Olive polyphenol effects in a mouse model of chronic ethanol addiction. Nutrition 2017; 33:65-69. DOI:10.1016/j.nut.2016.08.014

126. Carito V, Ceccanti M, Tarani L, Ferraguti G, N. Chaldakov G, Fiore M. Neurotrophins' modulation by olive polyphenols. Curr Med Chem 2016; 23:3189-3197. DOI: 10.2174/0929867323666160627104022

127. Carito V, Ceccanti M, Chaldakov G, Tarani L, De Nicolò S, Ciafrè S, et al. Polyphenols, nerve growth factor, brain-derived neurotrophic factor, and the brain. In: Bioactive Nutraceuticals and Dietary Supplements in Neurological and Brain Disease: Prevention and Therapy 2016; 65-71. DOI:10.1016/B978-0-12411462-3.00007-2

128. De Nicolò S, Carito V, Fiore M, Laviola G. Aberrant behavioral and neurobiologic profiles in rodents exposed to ethanol or red wine early in development. Curr Dev Disord Reports 2014; 1:173-180. DOI:10.1007/s40474014-0023-5

129. Fiore M, Mancinelli R, Aloe L, Laviola G, Sornelli F, Vitali M, et al. Hepatocyte growth factor, vascular endothelial growth factor, glial cell-derived neurotrophic factor and nerve growth factor are differentially affected by early chronic ethanol or red wine intake. Toxicol Lett 2009; 188:208-213. DOI:10.1016/j.toxlet.2009.04.013

130. Ceccanti M, Mancinelli R, Tirassa P, Laviola G, Rossi $\mathrm{S}$, Romeo M, et al. Early exposure to ethanol or red wine and long-lasting effects in aged mice. A study on nerve growth factor, brain-derived neurotrophic factor, hepatocyte growth factor, and vascular endothelial growth factor. Neurobiol Aging 2012; 33:359-367. DOI:10.1016/j.neurobiolaging.2010.03.005 
131. Fiore M, Laviola G, Aloe L, di Fausto V, Mancinelli R, Ceccanti M. Early exposure to ethanol but not red wine at the same alcohol concentration induces behavioral and brain neurotrophin alterations in young and adult mice. Neurotoxicology 2009; 30:59-71. DOI:10.1016/j. neuro.2008.11.009

132. Ceccanti M, De Nicolò S, Mancinelli R, Chaldakov G, Carito V, Ceccanti M, et al. NGF and BDNF long-term variations in the thyroid, testis and adrenal glands of a mouse model of fetal alcohol spectrum disorders. Ann Ist Super Sanita 2013; 49:383-390. DOI:10.4415/ANN-1304-11

133. Carito V, Ceccanti M, Ferraguti G, Coccurello R, Ciafrè S, Tirassa $\mathrm{P}$, et al. NGF and BDNF alterations by prenatal alcohol exposure. Curr Neuropharmacol 2017; 15: DOI: 10.2174/1570159X15666170825101308

134. De Simone R, Aloe L. Influence of ethanol consumption on brain nerve growth factor and its target cells in developing and adult rodents. Ann Ist Super Sanita 1993; 29:179-183.

135. Angelucci F, Fiore M, Cozzari C, Aloe L. Prenatal ethanol effects on NGF level, NPY and ChAT immunoreactivity in mouse entorhinal cortex: A preliminary study. Neurotoxicol Teratol 1999; 21:415-425. DOI:10.1016/ S0892-0362(99)00005-7

136. Aloe L, Tirassa P. The effect of long-term alcohol intake on brain NGF target cells of aged rats. Alcohol 1992; 9:299-304. DOI:10.1016/0741-8329(92)90070-q

137. Lhullier AC, Moreira FP, da Silva RA, Marques MB, Bittencourt G, Pinheiro RT, et al. Increased Serum Neurotrophin Levels Related to Alcohol Use Disorder in a Young Population Sample. Alcohol Clin Exp Res 2015; 39:30-35. DOI:10.1111/acer.12592

138. Ceccanti M, Coccurello R, Carito V, Ciafrè S, Ferraguti G, Giacovazzo G, et al. Paternal alcohol exposure in mice alters brain NGF and BDNF and increases ethanolelicited preference in male offspring. Addict Biol 2016; 21:776-787. DOI:10.1111/adb.12255

139. Miller MW, Mooney SM. Chronic exposure to ethanol alters neurotrophin content in the basal forebraincortex system in the mature rat: Effects on autocrineparacrine mechanisms. J Neurobiol 2004; 60:490-498. DOI:10.1002/neu.20059

140. Mooney SM, Miller MW. Nerve growth factor neuroprotection of ethanol-induced neuronal death in rat cerebral cortex is age dependent. Neuroscience 2007;
149:372-381.

141. Li Z, Ding M, Thiele CJ, Luo J. Ethanol inhibits brainderived neurotrophic factor-mediated intracellular signaling and activator protein-1 activation in cerebellar granule neurons. Neuroscience 2004; 126:149-162. DOI:10.1016/j.neuroscience.2004.03.028

142. Aloe L, Fiore M. TNF-alpha expressed in the brain of transgenic mice lowers central tyroxine hydroxylase immunoreactivity and alters grooming behavior. Neurosci Lett 1997; 238:65-68. DOI:10.1016/S03043940(97)00850-1

143. Heberlein A, Schuster R, Kleimann A, Groh A, Kordon A, Opfermann B, et al. Joint effects of the epigenetic alteration of neurotrophins and cytokine signaling: A possible exploratory model of affective symptoms in alcoholdependent patients? Alcohol Alcohol 2017; 52:277-281. DOI:10.1093/alcalc/agw100

144. Rassi AJ, Rassi A, Marcondes de Rezende J. American trypanosomiasis (Chagas disease). Infect Dis Clin North Am 2012; 26:275-291. DOI:10.1016/j. idc.2012.03.002

145. Rassi AJ, Rassi A, Marin-Neto JA. Chagas disease. Lancet (London, England) 2010; 375:1388-1402. DOI:10.1016/ S0140-6736(10)60061-X

146. Holmes PH, Miles MA. The trypanosomiases. $C A B$ Int Wallingford, UK 2004.

147. Sofroniew M V, Howe CL, Mobley WC. Nerve Growth Factor Signaling, Neuroprotection, and Neural Repair. Annu Rev Neurosci 2001; 24:1217-1281. DOI:10.1146/ annurev.neuro.24.1.1217

148. Chuenkova M V., Pereira MA. The T. cruzi transsialidase induces PC12 cell differentiation via MAPK/ ERK pathway. Neuroreport 2001; 12:3715-3718. DOI:10.1097/00001756-200112040-00022

149. Hoff R, Teixeira RS, Carvalho JS, Mott KE. Trypanosoma cruzi in the cerebrospinal fluid during the acute stage of Chagas' disease. N Engl J Med 1978; 298:604-606. DOI:10.1056/NEJM197803162981106

150. De Souza MM, Andrade SG, Barbosa AA, Santos RTM, Alves VAF, Andrade ZA. Trypanosoma cruzi strains and autonomic nervous system pathology in experimental Chagas disease. Mem Inst Oswaldo Cruz 1996; 91:217-224. DOI:10.1590/S007402761996000200018

151. Tafuri WL. Pathogenesis of lesions of the autonomic nervous system of the mouse in experimental acute Chagas' 
disease. Light and electron microscope studies. Am J Trop Med Hyg 1970; 19:405-417.

152. Molina HA, Cardoni RL, Rimoldi MT. The neuromuscular pathology of experimental Chagas' disease. J Neurol Sci 1987; 81:287-300. DOI:10.1016/0022510X(87)90104-3

153. Said G, Joskowicz M, Barreira AA, Eisen H. Neuropathy associated with experimental Chagas' disease. Ann Neurol 1985; 18:676-683. DOI:10.1002/ana.410180609

154. Bocchi EA, Bestetti RB, Scanavacca MI, Cunha Neto E, Issa VS. Chronic Chagas heart disease management: From etiology to cardiomyopathy treatment. J Am Coll Cardiol 2017; 70:1510-1524. DOI:10.1016/j.jacc.2017.08.004

155. Malik LH, Singh GD, Amsterdam EA. Chagas heart disease: An update. Am J Med 2015; 128:1251.e7-9. DOI:10.1016/j.amjmed.2015.04.036

156. Chuenkova M V, Pereiraperrin M. Neurodegeneration and neuroregeneration in Chagas disease. Adv Parasitol 2011; 76:195-233. DOI:10.1016/B978-0-12-3858955.00009-8

157. Chuenkova M V, PereiraPerrin M. Chagas' disease parasite promotes neuron survival and differentiation through TrkA nerve growth factor receptor. J Neurochem 2004; 91:385-394. DOI:10.1111/j.1471-4159.2004.02724.x

158. Palin MS, Mathew R, Towns G. Spinal neuroschistosomiasis. Br J Neurosurg 2015; 29:582-584. DOI:10.310 9/02688697.2015.1016890

159. Carod-Artal FJ. Neuroschistosomiasis. Expert Rev Anti Infect Ther 2010; 8:1307-1318. DOI:10.1586/eri.10.111

160. Ferrari TCA, Gazzinelli G, Correa-Oliveira R. Immune response and pathogenesis of neuroschistosomiasis mansoni. Acta Trop 2008; 108:83-88. DOI:10.1016/j. actatropica.2008.02.010

161. Nascimento-Carvalho CM, Moreno-Carvalho OA. Neuroschistosomiasis due to Schistosoma mansoni: a review of pathogenesis, clinical syndromes and diagnostic approaches. Rev Inst Med Trop Sao Paulo 2005; 47:179-184. DOI:S0036-46652005000400001

162. Pittella JEH. Neuroschistosomiasis. Brain Pathol 1997; 7:649-662. DOI:10.1111/j.1750-3639.1997.tb01080.x

163. Varilek GW, Weinstock J V., Pantazis NJ. Isolated hepatic granulomas from mice infected with Schistosoma mansoni contain nerve growth factor. Infect Immun 1991; 59:4443-4449.

164. Aloe L, Moroni R, Mollinari C, Tirassa P. Schistosoma mansoni infection enhances the levels of NGF in the liver and hypothalamus of mice. Neuroreport 1994; 5:10301032. DOI:10.1097/00001756-199405000-00003

165. Aloe L, Moroni R, Fiore M, Angelucci F. Chronic parasite infection in mice induces brain granulomas and differentially alters brain nerve growth factor levels and thermal responses in paws. Acta Neuropathol 1996; 92:300-305. DOI:10.1007/s004010050522

166. Aloe L, Moroni R, Angelucci F, Fiore M. Role of TNF- $\alpha$ but not NGF in murine hyperalgesia induced by parasitic infection. Psychopharmacology (Berl) 1997; 134:287292. DOI: $10.1007 / \mathrm{s} 002130050451$

167. Fiore M, Carere C, Moroni R, Aloe L. Passive avoidance response in mice infected with Schistosoma mansoni. Physiol Behav 2002;75:449-454. DOI:10.1016/S00319384(01)00661-8

168. Fiore M, Aloe L. Neuroinflammatory implication of Schistosoma mansoni infection in the mouse. Arch Physiol Biochem 2001; 109:361-364. DOI:10.1076/ apab.109.4.361.4247

169. Fiore M, Moroni R, Alleva E, Aloe L. Schistosoma mansoni: Influence of infection on mouse behavior. Exp Parasitol 1996; 83:46-54. DOI:10.1006/expr.1996.0047

170. Aloe L, Fiore M. Neuroinflammatory implications of Schistosoma mansoni infection: New information from the mouse model. Parasitol Today 1998; 14:314-318. DOI:10.1016/S0169-4758(98)01283-6

171. Fiore M, Alleva E, Moroni R, Aloe L. Infection with Schistosoma mansoni in mice induces changes in nociception and exploratory behavior. Physiol Behav 1998; 65:347-353. DOI:10.1016/S0031-9384(98)00171-1

172. Tuszynski MH, Blesch A. Nerve growth factor: from animal models of cholinergic neuronal degeneration to gene therapy in Alzheimer's disease. Prog Brain Res 2004; 146:441-449. DOI:10.1016/S0079-6123(03)46028-7

173. Tuszynski MH, Thal L, Pay M, Salmon DP, Sang UH, Bakay R, et al. A phase 1 clinical trial of nerve growth factor gene therapy for Alzheimer disease. Nat Med 2005; 11:551-555. DOI:10.1038/nm1239

174. Malkki H. Alzheimer disease: NGF gene therapy activates neurons in the AD patient brain. Nat Rev Neurol 2015; 11:548. DOI:10.1038/nrneurol.2015.170

175. Karami A, Eyjolfsdottir H, Vijayaraghavan S, Lind G, Almqvist P, Kadir A, et al. Changes in CSF cholinergic biomarkers in response to cell therapy with NGF in patients with Alzheimer's disease. Alzheimers Dement 2015; 11:1316-1328. DOI:10.1016/j.jalz.2014.11.008 
176. Tuszynski MH, Yang JH, Barba D, Hoi-Sang U, Bakay RAE, Pay MM, et al. Nerve growth factor gene therapy activation of neuronal responses in Alzheimer disease. JAMA Neurol 2015; 72:1139-1147. DOI:10.1001/jamaneurol.2015.1807

177. Parikh V, Evans DR, Khan MM, Mahadik SP. Nerve growth factor in never-medicated first-episode psychotic and medicated chronic schizophrenic patients: Possible implications for treatment outcome. Schizophr Res 2003; 60:117-123. DOI:10.1016/S0920-9964(02)00434-6

178. Machado-Vieira R, Manji HK, Zarate CAJ. The role of lithium in the treatment of bipolar disorder: convergent evidence for neurotrophic effects as a unifying hypothesis. Bipolar Disord 2009; 11 (Suppl 2):92-109. DOI:10.1111/j.1399-5618.2009.00714.x

179. Gorbachevskaya N, Bashina V, Gratchev V, Iznak A. Cerebrolysin therapy in Rett syndrome: Clinical and EEG mapping study. Brain Dev 2001 23:S90-93. DOI:10.1016/ S0387-7604(01)00349-7

180. Chaldakov GN, Fiore M, Ghenev PI, Beltowski J, Ranćić G, Tunçel N, et al. Triactome: Neuro-immune-adipose interactions. Implication in vascular biology. Front Immunol 2014; 5: DOI:10.3389/fimmu.2014.00130

181 Chaldakov GN, Aloe A, Hiriart M, Fiore M, Zhelezov M. Cognitive adiposcience: A gold mine to be unfolded. Adipobiology 2018; 10:75-79. 